\title{
Línguas de Sinais como Línguas de InTerlocução: o Lugar das Atividades Comunicativas no Contexto Escolar ${ }^{1}$ \\ Sign Languages as Languages of Interlocution: the Place of Communicative Activities IN THE SCHOOL CONTEXT
}

\author{
Cristina Broglia Feitosa de LACERDA ${ }^{2}$ \\ Marta GRÀCIA ${ }^{3}$ \\ Maria Josep JARQUE ${ }^{4}$
}

\begin{abstract}
RESUMO: O desenvolvimento escolar do aluno surdo depende de seu domínio de uma língua de sinais. Todavia, uma língua de sinais não é cotidianamente desenvolvida no ambiente familiar; assim, esse domínio precisa ser alcançado no espaço escolar, no qual se espera que o aluno surdo tenha pares em sua língua e possa interagir por meio dela. Contudo, o ambiente escolar tem pouca tradição de trabalhar com o desenvolvimento de língua oral/língua de sinais, focalizando atividades com língua escrita como meta. Sobre o aluno surdo, pouco se discute acerca do desenvolvimento da língua de sinais no espaço escolar. O professor bilíngue foca seu trabalho no ensino da língua majoritária como segunda língua na modalidade escrita, trabalhando com a língua de sinais, sem uma proposta clara de desenvolvimento dessa língua. Debates sobre práticas para aprimoramento da oralidade para o desenvolvimento do sujeito ouvinte indicaram a oportunidade de refletir sobre esses aspectos em relação aos alunos surdos. $\mathrm{O}$ foco deste artigo está, então, no debate desse tema, visando a formação de professores para aprimoramento dos usos da língua de sinais no espaço escolar.
\end{abstract}

PALAVRAS-CHAVE: Avaliação escolar. Escala de avaliação. Língua Brasileira de Sinais. Língua Catalã de Sinais. Educação dos Surdos. Educação Especial. Diálogo.

\begin{abstract}
The academic development of the deaf student depends on his/her mastery of a sign language. However, a sign language is not developed daily in the family environment; thus, this domain needs to be achieved in the school space, in which it is expected that the deaf student has peers in his/her language and can interact through it. All the same, the school environment has little tradition of working with the development of oral/sign language, focusing on activities with written language as a goal. Regarding the deaf student, little is discussed about the development of sign language in the school space. The bilingual teacher focuses his/her work on teaching the majority language as a second language in the written modality, working with sign language, without a clear proposal for the development of that language. Debates on practices to improve orality for the development of the hearing subject indicated the opportunity to reflect on these aspects in relation to deaf students. The focus of this paper is, therefore, on the debate on this theme, aiming at the training of teachers to improve the uses of sign language in the school space.
\end{abstract}

KEYWORDS: School evaluation. Evaluation scale. Brazilian Sign Language. Catalan Sign Language, Education of the deaf. Special Education. Dialogue.

\footnotetext{
${ }^{1}$ https://doi.org/10.1590/1980-54702020v26e0162

${ }^{2}$ Doutorado em Educação pela Universidade Federal de São Carlos (UFSCar). Docente Associada II do Departamento de Psicologia - Programa de Pós-Graduação em Educação Especial (PPGEEs) da UFSCar. São Carlos/São Paulo/Brasil.

E-mail: cbflacerda@gmail.com. ORCID: https://orcid.org/0000-0002-3250-1374

${ }^{3}$ Doctorado en Psicología - Universitat de Barcelona (UB). Docente Titular do Facultad de Psicología, Departamento de Cognición, Desarrollo y Psicología de la Educación. Barcelona/Espanha. E-mail: mgraciag@ub.edu.

ORCID: https://orcid.org/0000-0003-1280-4578

${ }^{4}$ Doctorado en Psicología de la Educación - Universitat de Barcelona (UB). Docente Asistente do Facultad de Psicología, Departamento de Cognición, Desarrollo y Psicología de la Educación. Barcelona/Espanha. E-mail: mj_jarque@ub.edu.

ORCID: https://orcid.org/0000-0003-3488-6041
} 


\section{INTRODUÇÃo: CONSIDERAÇÓES SOBRE LINGUAGEM, LÍNGUA E EDUCAÇÃo DE SURDOS ${ }^{5}$}

À luz do referencial teórico histórico-cultural, a linguagem, como é concebida, tem papel central na constituição dos sujeitos. Os indivíduos constituem-se a partir da internalização das formas culturais da atividade, em um curso de transformaçóes qualitativas dos seus modos de agir e de pensar. A linguagem ocupa papel fundamental nesse processo de transformaçóes que emergem e se consolidam nas relaçóes sociais e na participação do sujeito na cultura (Vygotsky, 1979, 1984).

Para o autor, a trajetória principal do desenvolvimento psicológico da criança é de progressiva individuação, ou seja, trata-se de um processo que se origina nas relaçóes sociais, interpessoais, e transforma-se em características inteiramente novas, no plano intrapessoal. Assim, a linguagem da criança, desde seu início, é essencialmente social; ela se desenvolve no plano das interaçóes sociais, nas relaçóes interpessoais e vai progressivamente tornando-se também individual com base nos processos de conversão/internalização.

As estruturas do discurso, quando dominadas pela criança, transformam-se nas estruturas básicas do seu pensamento, pois "o desenvolvimento do pensamento é determinado pela linguagem, ou seja, pelos instrumentos lingüísticos do pensamento e pela experiência sócio-cultural da criança”" (Vygotsky, 1979, p. 73).

A linguagem, tanto do outro como da própria criança, assume um papel central também na internalização das funções psicológicas superiores. Todas as funçôes mentais são processos mediados por signos, que são os meios fundamentais para a orientação e a organização dessas funçôes. Por participar da constituição do pensamento, a linguagem exerce uma influência direta nas funçóes mentais, propiciando uma transformação na atenção, na memória e no raciocínio, entre outras (Vygotsky, 1979, 1984; Góes, 1996).

Concebida, então, como instância de significação do homem com as coisas, com outros homens e consigo próprio, é na linguagem que o desenvolvimento cultural do homem é constituído (Pino, 2005). Dessa forma, a linguagem desempenha um papel fundamental no desenvolvimento de modo geral e é a mais direta expressão da natureza da consciência humana.

A consciência se reflete na palavra da mesma forma que o sol em uma pequena gota d'água. A palavra é para consciência o que o microcosmo é para o macrocosmo, o que a célula é para o organismo, o que o átomo é para o universo. É o microcosmo da consciência. A palavra significativa é o microcosmo da consciência humana. (Vygotsky, 1984, p. 147).

Além disso, é a língua, como sistema de signos, que cria condições para a interação entre indivíduos e o partilhar de uma mesma cultura. É também na e pela linguagem que os conhecimentos são construídos, pois, ao partilharem um sistema de signos constitutivos de uma língua, os sujeitos podem, além de desenvolverem uma compreensão mútua, colocar em circulação os múltiplos sentidos presentes na linguagem. É ainda pela linguagem que as categorias conceituais podem ser construídas, organizando suas experiências, em uma atividade mediadora entre os sujeitos e os objetos do conhecimento.

${ }^{5}$ Este estudo foi desenvolvido com apoio financeiro da Fundação de Amparo à Pesquisa do Estado de São Paulo (FAPESP) Proc. 2016/13276-2 em colaboração com Projeto aprovado pela Universidade de Barcelona EDU2015-63616-P (Ministerio de Economía, Industria y Competitividad, Gobierno de España). 
Considerando-se o papel central da linguagem para a constituição dos sujeitos e o fato de que a língua de sinais é capaz de propiciar a constituição dos surdos como sujeitos, uma educação que vise propiciar o pleno desenvolvimento dos alunos surdos deve estar atenta à especificidade de seu desenvolvimento de linguagem e à sua dificuldade de acesso à cultura majoritária, se essa mediação ocorrer, unicamente, pela linguagem oral.

$\mathrm{Na}$ maioria das famílias a primeira língua da criança é a língua dos seus pais. Então as crianças surdas com pais surdos são expostas à língua de sinais muito cedo a adquirindo sem esforços. Muitos pesquisadores reconheceram que as crianças surdas filhas de pais surdos têm um melhor desempenho acadêmico e psicológico que as crianças surdas filhas de pais ouvintes. Uma razão para isso é que os pais surdos têm uma melhor aceitação da surdez, além disso, esses pais possuem expectativas mais realistas com relação ao sujeito surdo, aceitando seus filhos como eles são. Um outro fator de extrema relevância é o uso da língua de sinais entre os pais e a criança, o qual favorece sua constituição enquanto sujeito social de forma harmoniosa.

Apesar da importância da língua de sinais, a maioria dos surdos é exposta primeiramente à linguagem oral, língua de seus pais ouvintes e não à língua de sinais. Em muitos casos, o fato da criança surda não dominar a linguagem oral e nem ter experiências linguísticas ricas na língua de sinais, pode causar um significativo atraso de linguagem. Pelo fato da maioria das famílias serem ouvintes, as crianças surdas acabam tendo poucas oportunidades para adquirir a língua de sinais. (Guarinello \& Lacerda, 2014, p. 517).

Assim, destaca-se que a principal necessidade especial de sujeitos surdos é seu acesso a uma língua que seja compreensível para eles. Cabe destacar que o impedimento de acesso à língua usada pela maioria ouvinte é o que os exclui dos processos sociais e de desenvolvimento. Trata-se de barreiras escolares ou de aprendizagem que a escola e a sociedade impóem (ainda que nem sempre de forma consciente) e que dificultam o sucesso escolar dos alunos surdos (Gràcia, Sanlorien, \& Segués, 2016). Além disso, diferentes autores evidenciam os efeitos que tem a privação linguística em crianças surdas, já que algumas alterações no desenvolvimento têm sua origem em uma exposição pobre à comunicação e à linguagem, por falta de acessibilidade do material linguístico oferecido durante o período crítico (Humphries et al., 2014; Lu, Jones, \& Morgan, 2016).

No Brasil, na atualidade, a Educação de Surdos está amparada pelo Decreto № 5.626, de 22 de dezembro de 2005, que afirma o direito da pessoa surda a uma educação bilíngue, que contemple seu direito linguístico de ter acesso aos conhecimentos sociais e culturais em uma língua que lhe seja acessível. Tal proposta de escolarização pressupóe que os educandos surdos tenham acesso à Língua Brasileira de Sinais (Libras) em situaçóes dialógicas favorecedoras de seu desenvolvimento linguístico a partir do contato com interlocutores fluentes nas duas línguas envolvidas - a Língua de Sinais e a Língua Portuguesa. Nessa direção, os educadores precisam ter domínio tanto das línguas quanto dos modos peculiares de funcionamento de cada uma delas em seus diferentes usos sociais. Tal domínio, tanto por parte dos alunos como por parte dos docentes, é fundamental para possibilitar que o surdo tenha acesso aos conhecimentos de mundo e que possa trabalhá-los tanto na Libras como em Português. Naçóes que optaram por essa abordagem oficialmente revelam resultados muito satisfatórios no que diz respeito ao desenvolvimento e à aprendizagem das pessoas surdas (Lissi, Svartholm, \& González, 2012; Svartholm, 2014). 
Ao mesmo tempo, a atual política educacional de inclusão defende que o público-alvo da educação especial (PAEE) frequente escolas comuns próximas a seus domicílios, compreendendo a inclusão com ênfase apenas na aceitação social da presença desses alunos em salas de aula no ensino regular. Entretanto, se o objetivo é oferecer condiçóes iguais (inclusivas) de aprendizagem e de desenvolvimento, os alunos surdos precisam ser incluídos em ambientes bilíngues, no qual circulem a Libras e a Língua Portuguesa e isso náo pode ser alcançado se o aluno surdo não tiver pares e educadores competentes em Libras para se relacionarem com ele. Góes e Tartuci (2002) e Lacerda (2006) debatem e justificam a necessidade de inclusão de alunos surdos a partir do respeito à sua língua, à sua necessidade de desenvolver esta língua e, portanto, do seu direito a conviver com ouvintes e outros surdos em seu espaço escolar ${ }^{6}$. Faz-se necessário que o aluno surdo, além de estar presente (matriculado), participe efetivamente das atividades escolares e que progrida em seus conhecimentos. Só dessa forma um processo inclusivo pode ser reconhecido como exitoso (Gràcia, Sanlorien, \& Segués, 2016).

Assim, o desenvolvimento do aluno surdo depende da sua competência em língua de sinais (Fernandes, 2006; Lacerda \& Santos, 2013; Lodi, 2004). São as práticas dialógicas que promovem o desenvolvimento de língua e de linguagem, e a criança surda precisa muitíssimo dessa oportunidade (Moura, 2013). Como afirmado anteriormente, essa competência em língua de sinais precisa ser alcançada principalmente no ambiente escolar. As famílias são demandadas continuamente para que aprendam a língua de sinais e a usem com seus filhos; contudo, mesmo que as famílias se interessem e se esforcem para o uso dessa língua, elas serão geralmente iniciantes e, por vezes, menos proficientes que seus filhos. Dessa forma, é fundamental que as famílias se apropriem da língua de sinais, e as usem, mas ainda assim a escola terá um papel importante no aprimoramento linguístico desses alunos.

\section{DesenVolvimento: InTERAÇÁO COMUniCATIVA EM SAlA DE AUla}

Neste ponto, será necessário esclarecer que as línguas de sinais são línguas que se materializam na modalidade gesto-visual e são usadas pelas comunidades surdas para as interaçóes sociais ${ }^{7}$ (Jarque, 2011, 2016). Ela desempenha nas relaçóes sociais o mesmo papel que a oralidade desempenha para os sujeitos ouvintes. A princípio, não parece adequado tratar uma língua de sinais como uma língua oral, já que ela não o é; todavia, as práticas que envolvem seus usos, os textos que produz são similares aos textos e aos usos das línguas orais, em sua modalidade de uso face a face, como ocorre nas relações sociais. Nesse sentido, é que propomos esta reflexão.

\footnotetext{
${ }^{6}$ Em nossas experiências de programas de inclusão bilíngue de alunos surdos (município de Piracicaba, São Paulo (SP), Campinas-SP, São Paulo-SP e São Carlos-SP) em redes municipais de ensino, as crianças surdas foram inseridas em escolas comuns consideradas polos de educação de surdos, de modo a possibilitar a convivência com alunos ouvintes e com alunos surdos, favorecendo que ambas as línguas (Libras e Português) circulassem no espaço escolar, permitindo que tanto os alunos surdos quanto os ouvintes ampliassem seus conhecimentos em Português e em Libras (Proc. CNPq 473073/2006-4; Proc. CNPq 303562/2010-2, FAPESP 2012/17330-9).

7 "A Libras, como toda Língua de Sinais, é uma língua de modalidade gesto-visual porque utiliza, como canal ou meio de comunicaçẫo, movimentos gestuais e expressôes faciais que são percebidos pela visão; portanto, diferencia-se da Língua Portuguesa, que é uma língua oral-auditiva por utilizar, como canal ou meio de comunicaçáo, sons articulados que sáo percebidos pelos ouvidos. Mas, as diferenças não estão somente na utilização de canais diferentes, estão também nas estruturas gramaticais de cada língua" (Revista da FENEIS, número 2:16, 2000).
} 
Assim, com base na discussão proposta por Jarque, Morales e Garrusta (2014), optou-se por diferenciar os termos "língua falada" e "língua oral", uma vez que o primeiro se refere ao canal de produção e de recepção (fono-articulatório e auditivo, respectivamente), opondo-se à língua escrita (transmitida por meio de signos gráficos) e língua sinalizada (produzida por meio de signos gestuais faciais, manuais e corporais). Já a língua oral faz referência a um conjunto de traços que definem a atividade linguística (oralidade) e que se opóe a situação de planejamento ou fixaçáo do texto, como o que acontece na modalidade escrita. Dessa forma, as línguas de sinais são utilizadas em contextos de "oralidade", à semelhança de línguas de grupos indígenas ou comunidades rurais que não têm tradição de uso de língua escrita.

Jarque, Morales y Garrusta (2014) indicam os trabalhos de Blanche-Benviniste (1998), Brown e Yule (1983), Chafe (1985), Olson (2001), Ong (1987), Tannen (1986) e Teberosky (1990), em busca de apresentar características das línguas usadas em situação de oralidade e em situação planejada, conforme visualizado no Quadro 1.

\begin{tabular}{|c|c|c|}
\hline Dimensóes & $\begin{array}{l}\text { Língua Oral } \\
\text { (oralidade) }\end{array}$ & Língua "planejada" e "fixada" (escrita) \\
\hline Contexto & $\begin{array}{l}\text { Ancora-se principalmente no contexto } \\
\text { situacional, físico e temporal imedia- } \\
\text { to; discurso com maior dependência } \\
\text { pragmática. }\end{array}$ & $\begin{array}{l}\text { Ancora-se pouco no contexto situacional, } \\
\text { físico e temporal imediato; discurso mais } \\
\text { autônomo. }\end{array}$ \\
\hline Interlocutores & $\begin{array}{l}\text { Simultaneidade temporal; interação face } \\
\text { a face. }\end{array}$ & Distância temporal. \\
\hline Preparação & Espontânea. & Permite planejar, corrigir e revisar. \\
\hline Traços formais & $\begin{array}{l}\text { Inclui marcas características (frases } \\
\text { inconclusas, titubeios, interjeiçõos, repe- } \\
\text { tiçōes desnecessárias, mudanças bruscas } \\
\text { de tema, etc.). }\end{array}$ & $\begin{array}{l}\text { Possibilita ordenamento de fatos e } \\
\text { presença mais marcada de mecanismos } \\
\text { coesivos. }\end{array}$ \\
\hline Memória & Apoia-se na memória pessoal. & $\begin{array}{l}\text { Apoia-se em um suporte (escrita, vídeo, } \\
\text { etc.). }\end{array}$ \\
\hline Processo e resultado & $\begin{array}{l}\text { A atividade produtora da linguagem e o } \\
\text { produto coincidem. }\end{array}$ & $\begin{array}{l}\text { Possibilita a separaçáo entre a atividade } \\
\text { produtora de linguagem e o seu resultado. }\end{array}$ \\
\hline
\end{tabular}

Quadro 1. Características principais da oralidade e da literalidade.

Fonte: Adaptado de Jarque, Morales y Garrusta (2014).

Contudo, é necessário destacar que oralidade e a escrita (ou a língua planejada) formam um contínuo discursivo, nem sempre sendo possível marcar as diferenças entre essas produçóes. A língua oral e a língua "fixada" (escrita ou gravada em vídeo, como é o caso das línguas de sinais, por exemplo), são categorias difusas com a presença de produçóes prototípicas e de produçóes marginais, como evidenciam os textos escritos para serem lidos ou a interação escrita em aplicativos móveis como o WhatsApp. Por tudo isso, considera-se a conversação face a face em uma língua de sinais como um exemplo prototípico de oralidade. 
Além disso, atualmente, é possível encontrar usos das línguas de sinais em contextos de "fixação" - quando os textos são planejados, preparados e registrados. Estes, em geral, são gravados em algum tipo de guia escrito em glosas ou palavras-chave na língua falada, ou mediante algum sistema de símbolos, como o SignWriting ${ }^{8}$, por exemplo. Constituem exemplos de "fixação" os vídeos disponíveis em boa parte das plataformas digitais (videoblogs, YouTube, canais institucionais das entidades dos movimentos sociais surdos; webs oficiais; entre outros) ou os vídeos de uso pessoal enviados por usuários de línguas de sinais via dispositivos móveis com finalidade de comunicação.

Jarque, Morales y Garrusta (2014) destacam também o enfoque plurilíngue dinâmico exposto no "Marco Comum Europeu de Referência para as Línguas", no qual o Conselho da Europa propóe, para a educação das línguas na Europa, um modelo construído a partir das seguintes características: ser multifuncional, flexível, aberto, dinâmico, motivador e anti-dogmático (Council of Europe, 2001). Trata-se, então, de uma proposta educativa em consonância com sua definição de bilinguismo e cujo fim último é contemplar os usuários e os aprendizes de uma língua como agentes sociais - membros de uma sociedade com tarefas diversas (não exclusivamente linguísticas) em uma diversidade de circunstâncias e contextos (Council of Europe, 2001). É por essa razão que se aproxima aqui o lugar das línguas de sinais na sala de aula em relação aos alunos surdos, ao lugar ocupado pela oralidade nas salas de aula em relação aos alunos ouvintes.

No que concerne às práticas de linguagem, o conceito visa, é claro, às dimensóes particulares do funcionamento da linguagem em relação às práticas sociais em geral, tendo a linguagem uma função de mediação em relação às últimas. No contexto da reflexão sobre a relação dos aprendizes com as práticas de linguagem, em geral, com aquelas que ocorrem nas escolas. Bautier (1995) forneceu, recentemente, esclarecimentos interessantes para este conceito. As práticas de linguagem implicam dimensōes, por vezes, sociais, cognitivas e lingüísticas do funcionamento da linguagem numa situação de comunicação particular. Para analisá-las, as interpretações feitas pelos agentes da situação são essenciais. Estas interpretações dependem da identidade social dos atores e das representaçóes que eles têm dos usos possíveis da linguagem e das funçóes que eles privilegiam de acordo com sua trajetória. Neste sentido, as práticas sociais "são o lugar de manifestaçōes do individual e do social na linguagem” (p. 203). Seu caráter é, conseqüentemente, heterogêneo e os papéis, ritos, normas e códigos que são próprios à circulação discursiva, dinâmicos e variáveis. A relação dos atores com as práticas de linguagem também varia e a distância que pode separá-los ou, ao contrário, aproximá-los tem efeitos importantes nos processos de apropriação. Estudar o funcionamento da linguagem como práticas sociais significa, então, analisar as diferenciações e variaçōes, em função de sistemas de categorizações sociais à disposição dos sujeitos observados. (Schneuwly \& Dolz, 1995, p. 6).

$\mathrm{Na}$ escola, a competência em língua oral é um dos objetivos do trabalho com a criança, percebido como aspecto fundamental do currículo básico e transversal a ser incorporado na programação didática e que se concretiza nas atividades cotidianas em sala de aula. Os Parâmetros Curriculares Nacionais (1998), as Diretrizes Curriculares, o Plano Nacional de Educação - Lei no 13.005 , de 25 de junho de 2014, em suas metas, apontam para a necessida-

\footnotetext{
${ }^{8} \mathrm{O}$ SignWriting é um sistema de escrita usado para escrever línguas de sinais. Essa escrita expressa as configuraçốes de mãos, os movimentos, as expressōes faciais e os pontos de articulação das línguas de sinais. Recuperado em 15 de fevereiro de 2020 de https://escritadesinais.wordpress.com/2010/08/16/o-que-e-signwriting/.
} 
de de que os alunos sejam capazes de comunicar-se com seus pares, em seu contexto escolar e cultural, e usar a linguagem como ferramenta para aprendizagem.

Ensinar e aprender língua oral implica ajudar os alunos a elaborar textos orais que contribuam para o desenvolvimento de suas capacidades para expor, argumentar, narrar, entre outras. Os professores assumem essa responsabilidade e incluem, em suas aulas, debates, exposiçóes, atividades de língua oral, com várias estratégias para avançar nesse campo. Assim, há um movimento para o trabalho com a oralidade na sala de aula e na formação de professores, defendendo a ideia de que quanto melhor o desempenho na oralidade melhor será o desempenho nos demais campos do conhecimento propostos pela escola (Cyrank \& Magalhães, 2012; Gràcia, Galván-Bovaira, \& Sánchez-Cano, 2017; Magalhães, 2008; Marcuschi, 2003). É comum nos documentos orientadores da Educação Básica (Rojo, 2009), por exemplo, ver uma fundamentação que aponta para o uso integrado das habilidades de falar, de escutar, de ler e de escrever. Todavia, ao olhar-se de perto, o esforço maior é sempre concentrado na aquisição e no domínio da leitura e da escrita.

Ainda que se coloque em evidência a necessidade de trabalhar de maneira integrada as quatro habilidades implicadas na competência linguística, com a finalidade de facilitar o acesso à linguagem acadêmica, tanto em sua dimensão oral como em sua dimensão escrita (Rojo, 2009), a ênfase maior está sempre nas atividades de desenvolvimento da linguagem escrita. Ensinar e aprender a falar e a escutar, para além de aspectos linguísticos formais, como no caso da pronúncia correta, correção morfossintática ou domínio semântico, supóe apenas abordar a proposta pragmática dos estudos da linguagem, voltando-se principalmente para os usos da linguagem em contextos formais e informais, reduzindo muito o que poderia ser trabalhado pela escola em termos de oralidade. "O ensino e a aprendizagem da práxis da linguagem significa ajudar os alunos na construção de textos orais que desenvolvam a competência de narrar, argumentar oralmente, ou conversar entre outras" (Gràcia et al., 2015, p. 19).

Existem na literatura numerosos apontamentos em diferentes perspectivas que contribuem para a reflexão sobre elementos que deveriam estar presentes nas aulas para promover o desenvolvimento da competência linguística (falar e escutar) no campo da didática das línguas orais (Ramos, 1999; Schneuwly \& Dolz, 2004). Gràcia, Galván-Bovaira, \& Sánchez-Cano (2017), apoiada em uma revisão cuidadosa, assume aportes da teoria histórico-cultural e propóe uma Metodologia Conversacional (MC) para o ensino da oralidade na sala de aula.

A metodologia conversacional propóe que o discurso oral seja, ao mesmo tempo, objeto de aprendizagem e mediador nos processos de aprendizagem dos demais conteúdos escolares, o qual supóe alcançar os objetivos de aprendizagem da língua oral comunicativa de maneira transversal. Em todas as matérias do currículo. (Gràcia, Sánchez-Cano, Galván-Bovaira, \& Galve, 2012, p. 25).

\section{Metodologia Conversacional no trabalho escolar}

A MC assume uma visão de aprendizagem em termos de construção, na qual se entende que o aluno seja ativo em seu processo de aprendizagem, compreendido como um processo de conhecimento no qual estão implicados aspectos cognitivos, afetivos, emocionais, relacionais e sociais (Coll, 2010). Nesse contexto, a metodologia pretende promover a exploração por parte dos professores de conhecimentos prévios, seu uso como elemento para 
introduzir novos conteúdos e para monitorar como se dá a aprendizagem significativa (Leite, 1994); as ajudas adequadas que o professor proporciona ao estudante, diversificadas quanto a sua tipologia, bem como com respeito ao momento, à maneira e ao grau de explicitação, como elementos que impregnam e estáo na base da metodologia conversacional (Rojo, 2009).

Nessa perspectiva, dá-se atenção especial aos aspectos contextuais e organizativos que contribuem para uma gestáo co-participativa da conversação por parte de todos os agentes implicados (alunos e professores); com destaque para a necessidade de que os objetivos, conhecimentos prévios, conteúdos e procedimentos de avaliação vinculados à língua oral sejam explicitados no desenho instrucional das diferentes matérias do currículo; e se considera o papel dos professores como modelo e guia, por meio do uso de diversas estratégias, para o ensino e a aprendizagem dos diferentes usos comunicativos da linguagem.

Assim três são as áreas de foco para a metodologia conversacional (Gràcia et al., 2012): contexto e gestão da comunicação; desenho instrucional; e funções comunicativas e estratégias. Uma primeira referência fundamental direciona-se aos contextos social e físico que se cria na classe. $\mathrm{O}$ professor, outros profissionais e alunos constituem o contexto social, enquanto os objetos na sala - mesas, cadeiras, materiais em geral - constituem o contexto físico. A maneira como se organizarão os contextos físico e social terá importância central para os tipos de atividades que serão desenvolvidas e terá influência sobre as estratégias docentes e sobre o desenvolvimento da competência linguística. Assim, a maneira como os professores dispóem o mobiliário, como distribuem os alunos em sala e em como o próprio professor se posiciona, constituem elementos fundamentais para os objetivos de práticas de aprimoramento da conversação face a face. Por exemplo, a distribuição de mesas e de cadeiras em círculo, a disposição dos alunos e do professor, favorecerá que se vejam uns aos outros, que os alunos se olhem e falem entre si e que mantenham autênticas conversações sobre os conteúdos que estão sendo tratados na sala de aula. Ainda, o posicionamento do professor na mesma altura da criança, para favorecer a conversação, também pode ser uma estratégia facilitadora. A disposição do mobiliário, dos alunos e do professor - e de outros profissionais que possam participar do espaço escolar - precisam estar ajustadas para que atividades que favoreçam o desenvolvimento linguístico possam ocorrer. "[...] sem dúvida, para a metodologia conversacional, as disposiçôes que permitem falar uns com os outros comodamente e de maneira natural, isto é, em rede, facilitarão a co-construção do conhecimento em relação aos diferentes conteúdos" (Gràcia et al., 2015, p. 21).

Cabe destacar que esse ponto é também muito importante na interlocução em língua de sinais. Uma sala de aula que não permita a visualização do conjunto dos colegas impede que a criança surda participe efetivamente de práticas dialógicas. Um aluno ouvinte se prejudica por não ver seu interlocutor, mas pode ouvi-lo. Já um aluno surdo que não tem a possibilidade de visualizar bem seu interlocutor, ver seus movimentos de mãos, corpo e face, está excluído do diálogo e, infelizmente, isso é bastante comum em salas de aula que recebem alunos surdos.

Um segundo elemento importante são as normas de comunicação. Na MC, valorizam-se as normas que contribuem para a autorregulação da conversação por parte dos alunos. Nesse sentido, é preferível evitar que seja sempre o professor aquele que regula a conversação, dando a palavra aos alunos apenas quando lhe convém, ou seja, quando considera que podem falar, quando não interrompem seu discurso ou até mesmo em momentos em que sobra algum 
tempo no final da aula. É necessário que o professor trabalhe em uma outra perspectiva. O que a MC propóe é que a aula seja um espaço aberto de diálogo, no qual a conversação, o discurso dirigido para o outro, a construção conjunta de diversos tipos de textos orais constitua um conteúdo e, ao mesmo tempo, seja um instrumento para a aprendizagem dos diversos conteúdos escolares. Para tal, as normas de conversação precisam estar direcionadas estrategicamente de modo que os alunos sejam eles mesmos quem progressivamente se autorregulem nas conversaçóes, seja em pequenos grupos, em pares, em grupos maiores, seja no grupo classe. A referência explicita às normas de conversação será então um elemento importante a ser trabalhado em sala de aula (Gràcia et al., 2015).

Nesse sentido, faz-se necessário também o uso de estratégias, mais ou menos implícitas, que potencializem a participação de todos os alunos nas conversaçóes, sem que estes se sintam necessariamente obrigados a participar. Assim, o professor deve fazer uso de estratégias comunicativas que tenham como objetivo potencializar a necessidade de dizer algo, de defender ideias, de compartilhar experiências próprias, de comentar o que foi dito pelos companheiros, de dirigir-se a eles, de repetir o que acaba de dizer um companheiro destacando algum aspecto, de enunciar dúvidas em voz alta, e também de defender claramente que não está compreendendo a conversação, sem que isso seja considerado um problema, mas, sim, como um estímulo e uma meta que, entre muitas estratégias, terá de ser resolvida conjuntamente.

Há também outro aspecto muito pouco presente nas salas de aula onde as línguas de sinais comparecem. É muito frequente a criança surda permanecer em uma posição de quem recebe a comunicação - o professor fala para ela - e ela apenas responde às demandas do professor sem efetivamente saber como usar a língua para manifestar dúvidas, problematizar temas, concordar, discordar, questionar ou colocar-se discursivamente, ocupando adequadamente turnos discursivos (Lodi \& Luciano, 2014).

Na MC, o desenho instrucional parte da consideração de que a língua oral é uma competência a ser desenvolvida. Nessa perspectiva, entende-se que os objetivos, os conteúdos, as atividades e as propostas de avaliação não só devem estar incluídos na programação de cada matéria, mas que é necessário ser explicitado em classe, em graus e momentos diferentes, ao longo de uma disciplina escolar. Explicitar significa fazer chegar aos alunos, de modo claro, da forma que o professor considere necessária e adequada - ao nível que estão, as características dos alunos, o tipo de escola e as diferentes culturas existentes, as necessidades particulares de apoio de alguns alunos - os objetivos vinculados à competência em língua oral que se está trabalhando. Quando o docente recorda aos alunos os conteúdos e os objetivos que estão trabalhando, o que já dominam, o que "sabem fazer" com a linguagem, suas habilidades discursivas, o vocabulário que aprenderam, as diferentes maneiras que conhecem para fazer perguntas (mais ou menos formais), para obterem informaçôes, está contribuindo para que tomem consciência do que aprenderam.

Além disso, ao discutir-se, com eles, e explicar-se o que será proposto na continuidade dos trabalhos, qual será o passo seguinte, como aprenderão e ainda como serão avaliados, estar-se-á contribuindo para que os alunos sejam mais ativos. Se, para tudo isso, o docente o faz usando a língua oral, dando pistas e ajudas para que reflitam sobre a linguagem que estão usando, o professor também colaborará para incrementar a capacidade metalinguística de seus alunos (Gràcia et al., 2015). 
Assim sendo, o professor pode preparar atividades de modo que os alunos tenham a oportunidade de dizer quais açóes gostariam de realizar, seus objetivos e conteúdos (por exemplo: tipo de texto e gênero que preferem continuar aprendendo), o que também contribui para que sua dedicação e seu compromisso com a atividade seja maior, repercutindo positivamente nos resultados de aprendizagem. A participação ativa dos alunos na avaliação também é um elemento relevante para a $\mathrm{MC}$ seja ao revisar suas próprias produçóes e intervençóes durante uma atividade de discussão; seja ao participar de debates; levantar discussóes sobre a maneira que devem proceder para resolver um problema ou se posicionar em qualquer outra atividade de produção oral. A finalidade principal ao se planejarem as atividades de ensino e de aprendizagem implica que os alunos saibam construir textos orais (expositivos, instrutivos, argumentativos, narrativos) referidos à educação física, à matemática, ao conhecimento do meio natural, social e cultural, ou sobre qualquer outra disciplina, e que, progressivamente, tornem-se conscientes do que estão fazendo.

Apontamentos sobre estratégias comunicativas e linguísticas dos professores foram feitas (Gràcia et al., 2012), ao propor o discurso, para promover interação em rede, para sintetizar, modelar e contextualizar, para criar um clima de confiança em que os alunos se sintam confortáveis. Além dessas estratégias, também é necessário usar aquelas que incluem as emissôes ou as intervençóes dos alunos, em momentos e situaçóes diversas (quando o aluno chega atrasado e explica ao professor que chegou tarde porque perdeu o ônibus; quando o aluno formula uma pergunta depois de uma explicação do professor; quando responde a uma pergunta do professor ou de um amigo; entre outras). Quando o professor repete o que a criança disse da mesma maneira, quando corrige alguns aspectos morfossintáticos ou quando responde a uma pergunta e aproveita para esclarecer alguns aspectos, está favorecendo que a criança conheça outras formas de dizer ou imite seu modelo e, portanto, que avance em aspectos diversos de linguagem. Essas estratégias são fundamentais nos níveis iniciais de escolaridade, na Educação Infantil e séries iniciais do Ensino Fundamental, mas também para alunos que apresentam algum tipo de problema, dificuldades ou transtornos, ou, em geral, para aqueles com maiores necessidades de apoio. Em definitivo, as estratégias docentes apresentadas têm como finalidade principal ajudar os alunos a usarem as funçóes comunicativas da maneira mais diversificada possível, em contextos e situaçóes diferentes.

Os alunos deveriam terminar o Ensino Fundamental alcançando uma competência pragmática que lhes permitisse perguntar, pedir explicaçōes, fazer demandas de informação, questionar, apresentar dúvidas, argumentar, rebater, refletir sobre a linguagem em situaçóes diversas, mais ou menos formais ou acadêmicas, em relação a conteúdos (relacionado com as ciências, língua, experiências pessoais, mundo em que vivem, música, ficção, entre outros), com pessoas, auditórios e objetivos diversos. Todas essas funções e habilidades comunicativas são oportunidades de interação no campo de textos usados nas diversas comunicaçóes face a face, as quais podem ser realizadas corretamente do ponto de vista formal (fonética, fonologia, morfologia, sintaxe e semântica da língua). Essa meta pode ser alcançada unicamente se, na escola (para além de outros contextos), for dado às crianças a possibilidade de usar a linguagem, de construir textos orais diante de situaçóes diversas nas quais se sintam seguros, naquelas em que podem solicitar ajuda, naquelas em que companheiros, docentes e outros profissionais possam ser modelos a imitar; e nas que, em resumo, utilizem estratégias que facilitem esse trânsito 
e o desenvolvimento da competência linguística. Se isso é verdade para a criança ouvinte, mais ainda o é para a criança surda, que tem possibilidades restritas de interlocução com interlocutores proficientes. $\mathrm{O}$ papel da escola é ainda mais fundante e as açóes nessa direção precisam ser planejadas com muita atenção.

Destaca-se, ainda, que a escola atual precisa assumir a meta de considerar a família e o entorno da criança fora da escola como parte de seu projeto. O entorno que constitui a criança e sua família forma parte da escola, e a escola deve incorporar aos seus objetivos aquelas competências que a criança necessita desenvolver para poder ser membro de uma sociedade cada vez mais competitiva e complexa. Em definitivo, a escola precisa preparar as crianças para poder afrontar os desafios e as metas do mundo tal qual ele se apresenta.

O trabalho com a língua de comunicação e expressão situa-se nessa direção, já que a competência linguística, entre outras muitas incluídas no currículo, será um recurso imprescindível para todos os alunos e futuros cidadãos, mas especialmente para aqueles mais vulneráveis, em relação a dificuldades de linguagem, de aprendizagem e/ou outros transtornos, ou por pertencerem a famílias de baixa renda. Em relação a esse aspecto, novamente a questão da surdez ganha destaque. $\mathrm{O}$ aluno surdo é usuário de uma língua viso-gestual, minoritária nos espaços sociais. Se o uso que faz dessa língua e as formas de manifestar-se não forem valorizadas, mais e mais excluído ele será. A sociedade demanda a apropriação de línguas, o domínio cognitivo de conceitos e a segurança de enunciá-los; desse modo, a escola precisa ter o compromisso de favorecer que a criança surda seja competente nesses quesitos.

A pesquisa e a intervenção realizada por Gràcia e colaboradores indicou que as características ou a essência da MC se incorporaram, parcial ou totalmente, em algumas escolas que participaram de processos de formação nos últimos anos, com resultados bastante satisfatórios, para alunos ouvintes, usuário de uma língua oral. Não obstante, diferenças entre as características das escolas deram lugar a diferenças importantes nos resultados, indicando a necessidade de ajustes para cada diferente demanda (Gràcia, Ausejo, \& Porras, 2010). Os resultados mostram que as professoras, a partir de uma reflexáo conjunta sobre sua prática em sala de aula, podem ir modificando suas ideias acerca do que significa ensinar e aprender uma língua oral, bem como ir introduzindo elementos importantes em sua prática docente.

A partir de uma nova forma de organização da sala de aula e de mudanças nas atividades/metodologias propostas, as professoras promovem uma maior participação por parte dos alunos, que passam a ter maior consciência de que estão trabalhando e aprendendo conteúdos vinculados à língua oral, e que, além disso, suas capacidades comunicativas também servem para aprender de maneira mais significativa outros conteúdos escolares, que com as metodologias tradicionais seriam dificilmente alcançáveis (Gràcia et al., 2015).

\section{ConCLUSÃO: CONSIDERAÇÓES FINAIS}

Assumir as línguas de sinais como línguas com funcionamento de línguas orais abre espaço para debates em torno da pertinência de práticas para o aprimoramento do uso da oralidade, aqui voltadas ao desenvolvimento do sujeito ouvinte, e para a ampliação da fluência e uso das línguas de sinais pelos alunos surdos. 
A experiência da Metodologia Conversacional indica a pertinência de ampliar um trabalho nessa perspectiva para professores bilíngues que atuam nos espaços de educação de surdos, visando o desenvolvimento escolar de seus alunos por meio da língua de sinais. As reflexôes colocadas neste artigo indicam a necessidade de instrumentos voltados à formação de professores, em busca de favorecer o debate entre docentes e demais profissionais que trabalham com alunos surdos, para que sejam capazes de realizar autorreflexão com relação aos modos como ensinam e abordam uma língua de sinais no contexto da educação de surdos. Este texto abre a perspectiva de se promover uma participação maior por parte dos alunos surdos, que se tornam mais conscientes de seu uso de língua e de sua aprendizagem relativa aos conteúdos vinculados à língua de sinais e, também, sobre suas capacidades comunicativas fundamentais para aprender de modo mais significativo o conjunto dos conteúdos escolares.

\section{REFERÊNCIAS}

Blanche-Benveniste, C. (1998). Estudios lingüisticos sobre la relación entre oralidad y escritura. Barcelona: Gedisa.

Brown, G., \& Yule, G. (1983). Discourse Analysis. Cambridge: Cambridge University Press.

Chafe, W. (1985). Linguistic differences produced by differences between speaking and writing. In D. Olson, N. Torrance, \& A. Hildyard (Eds.), Literacy, Language and Learning: the nature and consequences of reading and writing (pp. 105-123). Cambridge: Cambridge University Press.

Coll, C. (2010). Enseñar y aprender, construir y compartir: procesos de aprendizaje y ayuda educativa. In C. Coll (Coord.), Desarrollo, aprendizaje y enseñanza en la educación secundaria (pp. 31-62). Barcelona: Ministerio de Educación, Graó.

Council of Europe. (2001). Common European Framework of Reference for Languages: Learning, Teaching, Assessment. Cambridge: Cambridge University Press.

Cyrank, L. F de M., \& Magalhães, T. G. (2012). O trabalho com a oralidade/variedades linguísticas no ensino de Língua Português. Veredas, 16(1), 59-74.

Decreto no 5.626, de 22 de dezembro de 2005. Regulamenta a Lei no 10.436, de 24 de abril de 2002. Dispóe sobre a Língua Brasileira de Sinais - LIBRAS. Recuperado em 10 de fevereiro de 2020 de http://www.planalto.gov.br/ccivil_03/_ato2004-2006/2005/decreto/d5626.htm

Fernandes, S. (2006). Letramentos na educação bilíngüe para surdos. In A. P. Berberian, C. C. Mori-de Angelis, \& G. Massi (Orgs.), Letramento: Referências em saúde e educação (pp. 117-144). São Paulo: Plexus.

Góes, M. C. R. de. (1996). Linguagem, surdez e educação. Campinas: Autores Associados.

Góes, M. C. R., \& Tartuci, D. (2002). Alunos surdos na escola regular: as experiências de letramento e os rituais da sala de aula. In A. C. B. Lodi, K. M. P. Harrison, S. R. L. de Campos, \& O. Teske (Orgs.), Letramento e Minorias (pp.110-119). Porto Alegre: Mediação.

Gràcia, M., Ausejo, R., \& Porras, M. (2010). Intervención temprana em comunicación y lenguaje: colaboración con las educadoras y familias de los niños. Revista de Logopedia, Fonoatría y Audiología, 30(4), 184-193. 
Gràcia, M., Galván-Bovaira, M. J., \& Sánchez-Cano, M. (2017). Análisis de las líneas de investigación y actuación en la enseñanza y el aprendizaje del lenguaje oral en contexto escolar. Revista Española de Lingüistica Aplicada, 30(1), 188-209.

Gràcia, M., Galván-Bovaira, M. J., Sánchez-Cano, M., Vega, F., Vilaseca, R., \& Rivero, M. (2015). Valoración de la enseñanza de la lengua oral: Escala EVALOE. Barcelona: Editorial Graó.

Gràcia, M., Sánchez-Cano, M., Galván-Bovaira, M. J., \& Galve, R. (2012). Com ensenyen a parlar el nostre alumnat? Formació des de la metodologia conversacional. Ámbits de Psicopedagogia, 36, 35-39.

Gràcia, M., Sanlorien, P., \& Segués, M. T. (2016). Inclusión y procesos afectivos, motivacionales y relacionales implicados en el aprendizaje escolar. Barcelona: Oberta UOC Publishing.

Guarinello, A. C., \& Lacerda, C. B. F. de. (2014). Educação bilíngue e atuação fonoaudiológica. In I. Q. Marchezan, H. J. da Silva, \& M. C. Tomé (Eds.), Tratado das especialidades em Fonoaudiologia (pp. 516-523). São Paulo: Guanabara Koogan.

Humphries, T., Kushalnagar, P., Mathur, G., Napoli, D. J., Padden, C., \& Rathmann, C. (2014). Ensuring language acquisition for deaf children: What linguists can do. Language, 90(2), e?31-e?52.

Jarque, M. J. (2011). Lengua y gesto en la modalidad lingüística signada. Anuari de Filologia. Estudis de Lingüística, 1, 71-99. DOI: https://doi.org/10.1344/AFEL2011.1.4

Jarque, M. J. (2016). ¿ ¿Son lenguas, las lenguas de signos? In M. C. Horno, I. Ibarretxe, \& J. L. Mendívil (Eds.), Panorama actual de la ciencia del lenguaje: primer sexenio de Zaragoza Lingüistica (pp. 61-84). Zaragoza: Prensas Universitarias.

Jarque, M. J., Morales, E., \& Garrusta, J. (2014). Valoración de las habilidades comunicativas en el contexto escolar en un modelo bilingüe intermodal. Actas del Congreso CNLSE 2014 sobre adquisición, aprendizaje y evaluación de la lengua de signos española (pp. 105-117). Madrid, Espanha: Real Patronato sobre Discapacidad.

Lacerda, C. B. F. de. (2006). A inclusão escolar de alunos surdos: o que dizem alunos, professores e intérpretes sobre esta experiência. Cad. CEDES, 26(69), 163-184.

Lacerda, C. B. F., \& Santos, L. F. (2013). Tenho um aluno surdo, e agora? Introdução à Libras e educação de surdos. São Carlos: EdUFSCar.

Lei $n^{o}$ 13.005, de 25 de junho de 2014. Aprova o Plano Nacional de Educação - PNE e dá outras providências. Recuperado em 15 de fevereiro de 2020 de http://www.planalto.gov.br/ccivil_03/_ Ato2011-2014/2014/Lei/L13005.htm

Leite, L. A. A. (1994). Pedagogia de projetos intervenção no presente. Presença Pedagógica, 2(8), 25-33.

Lissi, M. R., Svartholm, K., \& González, M. (2012). El Enfoque Bilingue en La Educación de Sordos: sus implicancias para la enseñanza y aprendizaje de la lengua escrita. Estudios Pedagógicos, 38(2), 299-320.

Lodi, A. C. B. (2004). A leitura como espaço discursivo de construção de sentidos: oficina com surdos Tese (Tese de Doutorado). Pontíficia Universidade Católica de São Paulo, São Paulo, Brasil.

Lodi, A. C. B., \& Luciano, R. T. (2014). Desenvolvimento da Linguagem de crianças surdas em língua brasileira de sinais. In A. C. B. Lodi, \& C. B. F. de Lacerda (Orgs), Uma escola duas línguas: letramento em lingua portuguesa e língua de sinais nas etapas iniciais de escolarização (pp. 33-50). Porto Alegre: Editora Mediação. 
Lu, J., Jones, A., \& Morgan, G. (2016). The impact of input quality on early sign development in native and non-native language learners. Journal of Child Language, 43(3), 537-552.

Magalhães, T. G. (2008). Por uma pedagogia do oral. Revista Signum, 11(2), 137-153.

Marcuschi, L. A. (2003). Oralidade e ensino de língua: uma questão pouco "falada". In A. P. Dionísio, \& M. A. Bezerra (Orgs.), O livro didático de português: múltiplos olhares (pp. 19-32). Rio de Janeiro: Lucerna.

Moura, M. C. (2013). Surdez e Linguagem. In C. B. F. de Lacerda, \& L. F. dos Santos (Orgs.), Tenho um aluno surdo, e agora? Introdução à Libras e educação de surdos (pp. 13-26). São Carlos: EdUFSCar.

Olson, D. R. (2001). What writing is?. Pragmatics and Cognition, 9, 239-258.

Ong, W. (1987). Oralidad y escritura. México: Fondo de Cultura Económica.

Parâmetros curriculares nacionais: terceiro e quarto ciclos do ensino fundamental: língua portuguesa. (1998). Brasília: MEC/SEF.

Pino, A. (2005). As marcas do Humano. São Paulo: Cortez.

Ramos, J. M. (1999). O espaço da oralidade na sala de aula. São Paulo: Martins Fontes.

Rojo, R. (2009). Letramentos múltiplos, escola e inclusão social. São Paulo: Parábola.

Schneuwly, B., \& Dolz, J. (1995). Os gêneros escolares: das práticas de linguagem aos objetos de ensino. Revista Brasileira de Educação, 11, 5-16.

Schneuwly, B., \& Dolz, J. (2004). Gêneros orais e escritos na escola. Campinas: Mercado de Letras.

Svartholm, K. (2014). 35 anos de educação bilíngue de surdos: e então?. Educação em Revista, 2, 33-50.

Tannen, D. (1986). Relative focus on involvement in oral and written discourse. In D. Olson, N. Torrance, \& A. Hildyard (Eds.), Literacy, Language and Learning: the nature and consequences of reading and writing (pp. 124-167). Cambridge: Cambridge University Press, 1985.

Teberosky, A. (1990). El lenguaje escrito y la alfabetización. Cultura y Vida, 3, 2-15.

Vygotsky, L. S. (1979). Pensamento e Linguagem. Lisboa: Antídoto.

Vygotsky, L. S. (1984). A Formação Social da Mente. São Paulo: Martins Fontes.

Recebido em: 29/10/2019

Reformulado em: 02/01/2020

Aceito em: 25/01/2020 


\section{Errata}

No artigo "Línguas de Sinais como Línguas de Interlocução: o Lugar das Atividades Comunicativas no Contexto Escolar"

"Sign Languages as Languages of Interlocution: the Place of Communicative Activities in the School Context"

Onde se lê: http://dx.doi.org/10.1590/s1413-65382620000100007

Leia-se: https://doi.org/10.1590/1980-54702020v26e0162 